\title{
На пути к более стратегическому партнерству: Укрепление ОБСЕ путем расширения сотрудничества ЕС и ОБСE
}

\author{
Дэвид Гэлбрейт, Андре Хертель, Стефан Воль $\phi^{*}$
}

\section{Аннотация}

В условиях, когда система безопасности в Европе становится все более хрупкой, ЕС и ОБСЕ сталкиваются с разными политическими и структурными проблемами. В то время как новый диалог в рамках «Стратегического компаса» ЕС подчеркивает стремление Евросоюза стать подлинным субъектом политики безопасности, ОБСЕ сталкивается с эрозией ценностного консенсуса и ослаблением ее исполнительных структур и институтов. Можно ли возродить ОБСЕ путем расширения сотрудничества с ЕС, и если да, то каким образом? В этой статье мы утверждаем, что ускорение развития политики безопасности ЕС не должно происходить за счет ОБСЕ. Напротив, сотрудничество между двумя организациями должно быть направлено на (1) укрепление ОБСЕ как самостоятельной организации по безопасности, (2) использование ОБСЕ в качестве подлинного форума для диалога и взаимного прояснения намерений и (3) использование основных сильных сторон обеих организаций, избегая дублирования в их деятельности.

\section{Ключевые слова}

ОБСЕ, ЕС, европейская безопасность, стратегическое партнерство, межорганизационное сотрудничество.

Для цитирования этой публикации: Гэлбрейт Д., Хертель А., Вольф С. На пути к более стратегическому партнерству: Укрепление ОБСЕ путем расширения сотрудничества ЕС и ОБСЕ // ОБСЕ Insights 3/2021 - Баден-Баден: Номос, 2022. URL: https://doi.org/10.5771/ 9783748911463-03

* Дэвид Гэлбрейт, кафедра политики, языков и международных исследований Университета Бата, dg341@bath.ac.uk

Андре Хертель, кафедра политических наук Йенского университета им. Фридриха Шиллера andre.haertel@gmail.com

Стефан Вольф, кафедра политических наук и международных исследований, Университет Бирмингема, s.wolff@bham.ac.uk 


\section{Введение}

ЕС и ОБСЕ проходят критический этап в определении своей роли в системе европейской безопасности. В ЕС варианты противодействия «новым и растущим угрозам и вызовам» обсуждаются в рамках дискуссии о «Стратегическом компасе» с целью «укрепления общей европейской культуры политики безопасности и обороны» и «определения правильных целей и конкретных задач его политики в будущем» ${ }^{1}$. Как отмечает Институт исследования проблем безопасности ЕС, задача обсуждений в рамках «Стратегического компаса» состоит в том, чтобы «согласовать политические ориентиры для развития политики ЕС в сфере безопасности и обороны, повысить эффективность его деятельности, устойчивость и потенциал, а также укрепить сотрудничество Союза с партнерами» ${ }^{2}$.

Перед ОБСЕ стоят другие проблемы, в том числе - нарастание напряженности в самой организации и снижение ее способности выполнять свой мандат по обеспечению всеобъемлющей безопасности ${ }^{3}$. Эти противоречия привели к эрозии консенсуса относительно норм, которые лежали в основе ОБСЕ начиная с 1970-х годов, и ослаблению ее исполнительных структур и институтов ${ }^{4}$. Это, в свою очередь, привело к снижению политической ценности организации для государств-участников и их готовности инвестировать в ее деятельность политический капитал и финансовые ресурсы. Как отмечает В. Цельнер, несмотря на очевидную необходимость ОБСЕ «как открытой площадки и деятельного субъекта в условиях, в которых не могут действовать другие МО» (международные организации) ${ }^{5}$, в европейской системе безопасности она стала маргинальной.

Обсуждение партнерских отношений ЕС с различными организациями в рамках дискуссии о «Стратегическом компасе» предоставляет ЕС и ОБСЕ новую возможность для определения характера их стратегического партнерства. Однако сотрудничество между ними уже имеет более долгую историю. Представители двух организаций неоднократно подчеркивали их общие интересы и преимущества сотрудничества ${ }^{6}$. В своей Глобальной стратегии 2016 года ЕС официально признает ОБСЕ в качестве общеевропейской организации, являющейся «основой европейской системы безопасности», и заявляет о том, что «усилит свою поддержку и сотрудничество с ОБСЕ, являющейся одной из опор европейской системы безопасности» ${ }^{7}$. ЕС подтвердил свою поддержку ОБСЕ в 2019 г. в обзоре хода реализации Глобальной стратегии ${ }^{8}$. Общая заинтересованность в укреплении безопасности и стабильности проявилась также в выделении в качестве приоритетных таких вопросов как надлежащее управление, борьба с организованной преступностью, противодействие коррупции и решение проблем безопасности, связанных с изменением климата9

Однако, как отмечают многие исследователи, на практике две эти организации в своей деятельности не следовали совместному подходу к вопросам безопасности и скорее действовали параллельно, но не вместе ${ }^{10}$. Несмотря на положительные примеры обратного, такие как сотрудничество между нынешней Специальной мо- 
ниторинговой миссией ОБСЕ в Украине и Консультативной миссией Европейского союза в Украине, данная тенденция скорее укрепилась и стала более распространенной. Напряженность в ОБСЕ возросла, а ЕС, особенно после подписания в 2007 г. Лиссабонского договора, стремится к большей стратегической автономии в качестве субъекта безопасности в Европе. Хотя более дееспособный и активный ЕС может (и должен) вносить более значимый вклад в европейскую безопасность, мы полагаем, что это не должно наносить ущерб ОБСЕ. Напротив, дело не в том, что «выживание ОБСЕ ... объективно отвечает интересам ЕС» ${ }^{11}$, а в том, что укрепление ОБСЕ служит национальным интересам 27 стран-членов ЕС и 57 государствучастников ОБСЕ ${ }^{12}$.

Ниже мы предлагаем три направления для углубления партнерских отношений между ними. Во-первых, необходима реалистичная оценка возможных результатов расширенного сотрудничества между ЕС и ОБСЕ. ОБСЕ не может стать инструментом, который служит только интересам безопасности ЕС, она нуждается в укреплении как самостоятельный субъект политики безопасности, потенциал и компетенции которого функционально отличаются от потенциала ЕC, но при этом значимы для решения проблем безопасности в областях, представляющих взаимный интерес.

Во-вторых, ЕС необходимо относиться к ОБСЕ, использовать и укреплять ее как форум для диалога и взаимного прояснения намерений. Это требует большей готовности к обсуждению с заинтересованными сторонами в России и странах «к востоку от ЕС» смысла и интерпретации принятых в рамках ОБСЕ обязательств и порождающих споры понятий, таких как «суверенитет» и «самоопределение», что позволит не допустить окончательного цементирования углубляющихся разделительных линий в системе европейской безопасности ${ }^{13}$.

В-третьих, более четкий фокус на совпадающих интересах 27 и 57 стран позволит вернуться к обсуждению основополагающих вопросов, избежать дублирования в деятельности и использовать основные сильные стороны обеих организаций во всех трех измерениях.

Мы изложим наши тезисы в нескольких разделах. В следующем разделе мы дадим краткий обзор текущего состояния сотрудничества ЕС с ОБСЕ. В третьем рассмотрим вопросы взаимодополняемости ЕС и ОБСЕ и препятствий для их взаимодействия в свете академической дискуссии о проблемах межорганизационного сотрудничества. В четвертом, заключительном разделе сформулированы наши политические рекомендации.

\section{Состояние сотрудничества между ЕС и ОБСЕ}

Несмотря на приверженность Европейских сообществ, а затем Европейского союза принципам СБСЕ-ОБСЕ, о чем свидетельствует подписание хельсинкского Заключительного акта (1975), парижской Хартии (1990) и Хартии европейской безопасно- 
сти (1999), сотрудничество между ними не рассматривалось всерьез как самостоятельная тема до начала 2000-х годов, пока в ОБСЕ не была принята «Платформа безопасности, основанной на сотрудничестве» (1999)14, а Европейский совет не принял «Выводы о сотрудничестве ЕС с ОБСЕ в предотвращении конфликтов, регулировании кризисов и постконфликтном восстановлении» $(2003)^{15}$. В решениях Европейского совета подчеркивалась необходимость «избегать дублирования» и обеспечения «эффективной взаимодополняемости», выделяя в качестве приоритетов сотрудничества миссии по установлению фактов, координацию на местах и взаимную дипломатическую поддержку ${ }^{16}$.

С 2006 года ЕС официально участвует в работе ОБСЕ: «На заседаниях директивных органов Европейской комиссии отводится одно место рядом с местом государства-участника, председательствующего в ЕС», и «представитель Европейской комиссии может выступать сразу после представителя государства-участника, председательствующего в ЕС» ${ }^{17}$. В 2018 году отношения между организациями были оформлены обменом письмами между генеральными секретарями ОБСЕ, Европейской комиссии и Европейской службы внешних действий, в которых две организации выразили приверженность проведению регулярных консультаций и оперативному сотрудничеству в областях, представляющих взаимный интерес, во всех трех измерениях ОБСЕ ${ }^{18}$. Помимо этого Верховный представитель ЕС по иностранным делам и политике безопасности, занимающий также пост заместителя председателя Европейской комиссии, обычно участвует в проводимых в декабре ежегодных встречах Совета министров ОБСЕ.

Работу ЕС в ОБСЕ обеспечивает его постоянное представительство при международных организациях, расположенная в Вене. Семь сотрудников представительства занимаются конкретными институтами или тематическими направлениями деятельности ОБСЕ ${ }^{19}$. Помимо этого при Европейском совете создана рабочая группа по ОБСЕ и Совету Европы, которая занимается отношениями ЕС с этими организациями и координирует общую позицию государств-членов по обсуждаемым в них вопросам ${ }^{20}$.

Что касается ОБСЕ, то ее государства-участники не смогли достичь консенсуса по вопросу о создании бюро по связям в Брюсселе. В Вене за отношения между ОБСЕ и ЕС отвечает отдел внешнего сотрудничества канцелярии Генерального секретаря и старший сотрудник по внешнему сотрудничеству (со всеми организациями, расположенными в Брюсселе). Отсутствие в ОБСЕ более конкретных структур для поддержания отношений с ЕС, особенно в полевых миссиях, затрудняет систематическую координацию деятельности с Брюсселем.

До недавнего времени обе организации отдавали предпочтение гибким формам сотрудничества: нерегулярные встречи «троек» ЕС и ОБСЕ, встречи Генерального секретаря ОБСЕ с Верховным представителем ЕС по иностранным делам и политике безопасности и ежегодные встречи на уровне сотрудников секретариатов. В ходе обмена письмами в 2018 году были определены сферы общих интересов, в который 
вошел практически весь спектр деятельности ОБСЕ, включая предотвращение конфликтов и посредничество, борьбу с терроризмом, а также содействие укреплению верховенства права и надлежащего управления. Это затрудняет формирование повестки дня и определение стратегических приоритетов - проблема, которая еще более усугубляется частой сменой руководящих кадров с обеих сторон и структурной несовместимостью двух организаций, что осложняет определение надлежащих партнеров и установление эффективных отношений между ними.

\section{Взаимодополняемость и препятствия для взаимодействия}

Исследования проблем межорганизационного сотрудничества показали, что обмен ресурсами представляет собой основной стимул для сотрудничества между организациями. Международные организации сотрудничают, потому что они заинтересованы или зависят от конкретных материальных (средства на проекты, инфраструктура, персонал) или нематериальных (легитимность, опыт, репутация) ресурсов, которые может предоставить соответствующий партнер ${ }^{21}$. Таким образом, обмен ресурсами основан на взаимодополняющих интересах сотрудничающих организаций. Сближение политических линий также может стать важным стимулом для сотрудничества и обмена ресурсами.

ЕС стал ключевым источником финансирования ОБСЕ в тех областях, в которых интересы ЕС и потребности ОБСЕ совпадают. ЕС, безусловно, вносит основной вклад в деятельность Специальной мониторинговой миссии ОБСЕ в Украине, предоставляя в ее распоряжение персонал, оборудование и спутниковые снимки ${ }^{22}$. Благодаря сети своих делегаций в регионе ОБСЕ он также может оказывать конкретное содействие полевым миссиям ОБСЕ.

ОБСЕ, в свою очередь, обладает значительными (хотя и сокращающимися в настоящее время) возможностями по проведению встреч и формированию повестки дня, опытом и инструментами для предотвращения конфликтов, опытом тихой дипломатии и подлинно многосторонним мандатом в том, что касается деятельности в конфликтных ситуациях. По сравнению с ЕС, который в затяжных конфликтах в регионе ОБСЕ не воспринимается как нейтральная сторона, ОБСЕ с большей вероятностью будет принята в качестве посредника и (или) наблюдателя на местах. Несмотря на существующие политические разногласия между государствами-участниками ОБСЕ, организация остается одним из немногих форумов общеевропейского диалога и поэтому полезна для ЕС в плане поддержания институционализированного взаимодействия с Россией по вопросам безопасности и не только по ним. На местах ОБСЕ по-прежнему обладает бо́льшим опытом по сравнению с ЕС, в частности, в том, что касается посредничества в конфликтах. Полевые миссии ОБСЕ могут оказывать ЕС содействие, к примеру, в выяснении позиций и потребностей национальных меньшинств. Наконец, ОБСЕ, благодаря участию в 
ней центрально-азиатских государств, может стать связующим звеном в реализации стратегии ЕС в Центральной Азии.

Однако сотрудничество предполагает наличие определенных условий, выходящих за рамки потребностей организации в ресурсах. Среди них предпочтения государств-членов, неравномерное распределение влияния между ними и организацией, культура и открытость организации, роль опыта межорганизационного взаимодействия или предыдущей «практики сотрудничества», а также роль влиятельных третьих сторон ${ }^{23}$. Среди препятствий для более активного партнерства между ЕС и ОБСЕ - асимметричность их возможностей, бюджетов и структурных характеристик. ЕС не является международной организацией как таковой. Он располагает многомиллиардным бюджетом, а его институты - широкими полномочиями. Даже в своих внешних делах ЕС все больше отходит от межправительственного характера принятия решений. ОБСЕ находится на противоположном конце данного спектра: это - организация с менее сплоченным составом участников, неопределенным правовым статусом, обязательным консенсусом при принятии решений и годовым бюджетом чуть менее 140 млн евро ${ }^{24}$. Основным следствием этих асимметричных отношений являются понятные опасения ОБСЕ (разделяемые значительным числом государств-участников) того, что организация может оказаться в зависимости от ЕС или превратится в инструмент его внешней политики и политики безопасности.

Дальнейшая двойственность вытекает из различий в составе участников, мандатов и устремлений двух организаций. Хотя в ОБСЕ состоят все 27 стран-членов $\mathrm{EC}$, в число ее государств-участников входят также Россия, все другие постсоветские страны, США, Канада, Норвегия, Великобритания ${ }^{25}$. Вследствие намного большего разнообразия типов политических режимов и внешнеполитических ориентаций ее участников ОБСЕ не обладает той сплоченностью (и, соответственно, политическими и экономическими рычагами), которая характерна для ЕС, и является скорее «форумом», а не полноценной международной организацией ${ }^{26}$. По этой причине для эффективного сотрудничества государства-члены ЕС должны различать свои предпочтения как членов ЕС и как государств-участников ОБСЕ. Если ЕС не будет относиться к ОБСЕ как к самостоятельной организации по безопасности, то более тесное сотрудничество между ЕС и ОБСЕ, а значит и более заметное присутствие и влияние ЕС в ОБСЕ будет неприемлемо для России и других государств-участников, не входящих в ЕС.

Что касается мандатов и устремлений, то ЕС вкладывает значительные и все большие средства в то, чтобы стать организацией по безопасности. В отличие от него ОБСЕ пытается отстоять роль значимой организации в основных областях своей деятельности - предотвращении конфликтов и посредничестве, - занимаясь вопросами, по которым все государства-участники могут прийти к согласию, но которые являются второстепенными для ее мандата и могут быть более эффективно решены на других площадках. В этой связи возникают вопросы о том, насколько ОБСЕ вообще нужна Европейскому союзу для отстаивания его собственных интере- 
сов и не будет ли неизбежное дублирование деятельности способствовать дальнейшей маргинализации ОБСЕ.

Наконец, основой успешного сотрудничества между международными организациями является тщательное управление отношениями, особенно в случае отчасти совпадающего состава участников. Это предполагает согласованное понимание целей и задач сотрудничества, проведение регулярных встреч и разработку процессов взаимодействия ${ }^{27}$. Формирование механизма управления отношениями между ЕС и ОБСЕ до сих пор не завершено. Нынешние отношения между ними недостаточно институционализированы, и даже после обмена письмами в 2018 году высшие должностные лица признают необходимость дальнейших шагов в этом направлении. Действительно, похоже, что не существует простой схемы сотрудничества, к примеру, по увязке деятельности различных структур ОБСЕ с возможностями Еврокомиссии и инструментами финансирования деятельности по предотвращению и урегулированию конфликтов. Более того, список конкретных областей сотрудничества непоследователен и слишком длинен, поэтому имело бы смысл определить приоритеты и четкие ориентиры. Еще один критический аспект: часто восхваляемое повседневное неформальное сотрудничество, для которого существует мало фактических доказательств - в отличие от примеров частого дублирования и параллельной деятельности, задокументированных в исследованиях ${ }^{28}$. Более перспективное направление для управления отношениями между двумя организациями - роль, которую могла бы сыграть Х. Шмид, занимавшая в прошлом пост Генерального секретаря Европейской службы внешних действий, а в настоящее время являющаяся Генеральным секретарем ОБСЕ, выступая в качестве настоящего связующего звена и содействуя более эффективному сотрудничеству двух организаций.

\section{Политические рекомендации: области для расширения сотрудничества}

Основываясь на предложенных нами трех направлениях для совершенствования партнерских отношений между ЕС и ОБСЕ, мы рекомендуем семь конкретных шагов, которые ОБСЕ и ее государства-участники, а также ЕС и его государства-члены могли бы предпринять для укрепления сотрудничества между ними. Вместе они представляют собой новый подход, который (1) основан на реалистичной оценке того, чего можно достичь в результате расширения сотрудничества между ЕС и ОБСЕ, (2) характеризуется большей степенью открытости со стороны ЕС для взаимодействия с заинтересованными сторонами в России и странах «К востоку от ЕС» в рамках ОБСЕ и (3) позволяет избежать дублирования, используя основные сильные стороны обеих организаций во всех трех измерениях. 


\section{а) Укрепление механизмов предотвращения конфрликтов}

ЕС и ОБСЕ имеют различные, но частично совпадающие преимущества в сфере предотвращения конфликтов. В ЕС лучше разработаны инструменты решения структурных проблем, ведущих к возникновению конфликтов, в то время как ОБСЕ располагает опытом и потенциалом для их непосредственного предотвращения, но часто не имеет финансовых ресурсов для быстрого реагирования. Следовательно, расширение сотрудничества может быть направлено на бо́льшую интеграцию стратегий предотвращения конфликтов и их практической реализации. ОБСЕ могла бы помочь ЕС определить более четкие и точные критерии для оценки политики предотвращения конфликтов в его различных стратегиях, планах действий и программах. В свою очередь, ЕС следует увеличить финансовую поддержку (например, из средств Инструмента политики соседства, развития и международного сотрудничества) рассчитанных на несколько лет бюджетов ОБСЕ. Дополнительные средства могли бы быть направлены на активизацию сотрудничества в области мер по укреплению доверия в условиях затяжных конфликтов в регионе ОБСЕ и на деятельность Верховного комиссара по делам национальных меньшинств.

\section{б) Изменение приоритетов в области контроля над вооружениями}

Нормы и механизмы контроля над вооружениями, некогда являвшиеся краеугольным камнем деятельности и успеха ОБСЕ, ослабли по мере роста напряженности в организации и вооруженной эскалации конфликтов. «Структурированный диалог» в рамках ОБСЕ, в ходе которого обсуждаются современные и будущие вызовы и риски для безопасности в регионе ОБСЕ, о котором министры иностранных дел стран ОБСЕ договорились на встрече Совета в Гамбурге в декабре 2016 года, способен внести значительный вклад в восстановление эффективного режима контроля над вооружениями. Вклад ЕС в повышение эффективности «Структурированного диалога» мог бы заключаться в более активном обсуждении соответствующих вопросов на структурах ЕC, в том числе в Военном комитете Европейского Союза и Комитете по вопросам политики и безопасности. В свою очередь, эксперты ЕС могли бы принимать участие в неформальных рабочих группах и встречах военных экспертов, проводимых в рамках «Структурированного диалога», демонстрируя тем самым политическую и дипломатическую поддержку со стороны ЕС. 


\section{в) Содействие повышению взаимосвязанности}

И в ЕС, и в ОБСЕ сформирована повестка дня в области взаимосвязанности. В регионе ОБСЕ «К востоку от ЕС» альтернативу проекту политической и экономической интеграции ЕС представляет собой Евразийский экономический союз. Более того, китайская «Инициатива пояс и путь» предлагает еще один вариант политики взаимосвязанности. Сотрудничество ЕС и ОБСЕ могло бы предоставить возможность начать обсуждение вопросов, порождаемых конкуренцией между различными интеграционными проектами, и начать разработку основных правил, которые способствовали бы повышению уровня совместимости этих проектов. ЕС мог бы поддержать деятельность ОБСЕ по формулированию согласованной повестки дня «Взаимосвязанность $2.0 »^{29}$, направленной на содействие устойчивому и инклюзивному восстановлению после пандемии. Поскольку взаимосвязанность все чаще рассматривается в контексте проблем безопасности, 27 и 57 стран имеют очевидные общие интересы, когда речь идет о взаимосвязи между климатом и безопасностью, технологическим развитием и безопасностью, а также между управлением и безопасностью. Поддержка со стороны ЕС инициатив ОБСЕ, направленных на укрепление доверия в экономическом и экологическом измерении, например, в регионах Каспийского, Черного и Средиземного морей, могут служить точками доступа в критически важные регионы, принести ощутимую пользу местному населению и в конечном итоге способствовать налаживанию всестороннего и конструктивного обсуждения вопросов «жесткой» безопасности.

\section{г) Противодействие эрозии норм}

Всеобъемлющий подход ОБСЕ к безопасности опирается на основополагающие договоренности, согласованные государствами-участниками в Хельсинки в 1975 году и Париже в 1990 году и подтвержденные в астанинской Юбилейной декларации 2010 года. Поскольку в последнее десятилетие эти основы все чаще ставятся под вопрос, сотрудничество между ЕС и ОБСЕ должно быть направлено на формирование отстаивающих согласованные в ОБСЕ нормы альянсов государств, участвующих в работе обеих организаций и отражающих баланс мнений 27 и 57 стран. Такое сотрудничество могло бы принять форму «группы друзей», в работе которой принимали бы участие как государства-члены EC, так и расположенные к востоку и западу от Вены государства-участники ОБСЕ, не входящие в ЕС, и (или) сосредоточиться на деятельности конкретных институтов ОБСЕ, таких как Верховный комиссар по делам национальных меньшинств. 


\section{д) Активизация сотрудничества на местах}

Делегации ЕС есть во всех государствах-участниках ОБСЕ, а ОБСЕ в настоящее время имеет присутствия в 13 государствах-участниках (все - «к востоку от ЕС»). Тем не менее сотрудничество между делегациями ЕС и полевыми операциями ОБ$\mathrm{CE}$ часто носит эпизодический характер, ограничивается политической поддержкой и редко обеспечивает устойчивый источник финансирования для не обладающих достаточными ресурсами и перегруженных миссий ОБСЕ на местах. Поэтому установление и укрепление связей между делегациями ЕС, специальными представителями ЕС и посольствами его государств-членов, с одной стороны, и миссиями ОБСЕ, специальными представителями действующего Председателя и другими присутствиями на местах - с другой, должно стать приоритетным направлением сотрудничества между ЕС и ОБСЕ. Такое взаимодействие может предполагать реализацию инициатив в области образования и других ориентированных на молодежь инициатив.

\section{е) Расширение обмена знаниями и возможностей совместной подготовки кадров}

Создание общего пула гражданских экспертов ЕС и ОБСЕ и организация совместных тренингов способствовали бы «взаиморазвертываемости» и взаимному пониманию институциональной культуры двух организаций. Существующие конкретные проекты, заслуживающие рассмотрения в практическом плане, включают расширение поддержки Академии ОБСЕ в Бишкеке со стороны ЕС или его стран-членов. Другая возможность - взносы в натуральной форме от странчленов ЕС для подготовки сотрудников миссий ОБСЕ перед их развертыванием на местах. Это может быть сделано по примеру курсов подготовки персонала перед их направлением в состав Специальной мониторинговой миссии в Украине, проводимых Международным центром Вооруженных сил Австрии ${ }^{30}$.

ж) Использование инициатив в фрормате второго и «полуторного» «треков»

Вышеизложенные рекомендации можно было бы усовершенствовать благодаря более систематической поддержке обеими организациями инициатив в формате второго и «полуторного» «треков», цель которых заключалась бы в изучении мнений и представлений более широкого круга государств-участников о возможностях для расширения сотрудничество между ЕС и ОБСЕ, конкретных ожиданиях 27 и 57 стран, а также «красных линий» для государств-участников, не входящих в 
ЕС. Это соответствовало бы нашему ключевому предположению о том, что любое обсуждение сотрудничества ЕС с ОБСЕ должно быть сосредоточено на укреплении ОБСЕ как основной организации по обеспечению всеобъемлющей безопасности и сотрудничества на евроатлантическом и евразийском пространстве.

\section{Примечания}

1 Towards a Strategic Compass // European External Action Service. May 2021. URL; https://eeas .europa.eu/sites/default/files/towards_a_strategic_compass.pdf.

2 Finding direction with a Strategic Compass? Reflections on the future of EU security and defence. European Union Institute for Security Studies Event Report, 2021. P. 2. URL: https://w ww.2021 portugal.eu/media/5e3pjuwv/event-report-strategic-compass.pdf.

3 Гремингер Т. Повышение эффективности ОБСЕ: практические рекомендации бывшего Генерального секретаря // ОБСЕ Insights 1/2021 - Баден-Баден: Номос, 2022. URL: https://d oi.org/10.5771/9783848782895-01.

4 Global Europe Program Working Group on the Future of the OSCE: Uncommon Cause: The Future of the OSCE // TransAtlantic. - 2021. № 2. P. 2-4. URL: https://www.wilsoncenter.org/si tes/default/files/media/uploads/documents/Uncommon\%20Cause $\% 20-\% 20$ The $\% 20$ Future $\% 20$ of $\% 20$ the $\% 20$ OSCE\%20v2.pdf.

5 Zellner W. Using the OSCE More Effectively: Ideas and Recommendations. IFSH Paper for the Federal Foreign Office, November 2020. P. 14. URL: https://ifsh.de/file/publication/2021_OSZE -Studie/20210301_USING_THE_OSCE_MORE_EFFECTIVELY.pdf.

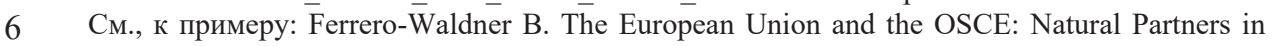
a Networked World // OSCE Yearbook 2006. - Baden-Baden: Nomos, 2007. P. 407-409. URL: https://ifsh.de/file-CORE/documents/yearbook/english/06/FerreroWaldner-en.pdf.

7 Общее видение, единый подход: сильная Европа. Глобальная стратегия Европейского Союза по внешней политике и политике безопасности. 2016. С. 25 // Официальный сайт Европейского союза. URL: https://eeas.europa.eu/sites/default/files/eu_global_strategy_ru.pdf.

Общее видение, единый подход: сильная Европа. Глобальная стратегия Европейского Союза по внешней политике и политике безопасности; The European Union's Global Strategy: Three years on, looking forward. 2019. Р. 20. // Официальный сайт EC. URL: https://eeas.euro pa.eu/sites/eeas/files/eu_global_strategy_2019.pdf.

9 См., к примеру: Eastern Partnership. 20 deliverables for 2020: Monitoring - State of Play in February 2020 // Официальный сайт EC. URL: https://ec.europa.eu/neighbourhood-enlargemen t/sites/default/files/monitoring_spring_2020_20_deliverables_for_2020.pdf.

10 Dijkstra H. et al. The EU's Partners in Crisis Response and Peacebuilding: Complementarities and Synergies with the UN and the OSCE // Global Affairs. 2018. № 2-3. P. 185-196; Galbreath D. Convergence Without Cooperation? The EU and the OSCE in the Field of Peacebuilding // S. Blockmans, J. Wouters, T. Ruys (eds.). The European Union and Peacebuilding: Policy and Legal Aspects. - The Hague: Asser Press, 2010. P. 175-194.

11 Bailes A.J.K., Haine J.-Y., Lachowski Z. Reflections on the OSCE-EU Relationship // OSCE Yearbook 2007. - Baden-Baden: Nomos, 2008. P. 76. URL: https://ifsh.de/file-CORE/documents/yearbook/english/07/BailesHaineLachowski-en.pdf.

12 См. также: Deutscher Bundestag. Antrag der Fraktionen CDU/CSU, SPD, FDP und BÜNDNIS 90/DIE GRÜNEN: 45 Jahre Schlussakte von Helsinki, 30 Jahre Charta von Paris - Die Organisation für Sicherheit und Zusammenarbeit in Europa für künftige Aufgaben stärken // 
Deutscher Bundestag. Drucksache 19/19140, 2020. URL: https://dip21.bundestag.de/dip21/btd/1 9/135/1913551.pdf.

13 Это особенно важно в свете июньского решения Совета ЕС 2021 г. не возобновлять проведение саммитов ЕС-Россия, вопреки совместному предложению Франции и Германии сделать это, чтобы после проведения встречи Путина и Байдена в Женеве 17 июня 2021 г. поддерживать отношения ЕС с Россией на том же уровне, что и отношения между США и Россией. Хотя возможности, которые ОБСЕ предоставляет в качестве форума, не могут заменить прямой диалог между ЕС и Россией, характер двусторонних отношений между EC и Россией не должны быть ориентиром для отношений с Россией в многостороннем формате ОБСЕ, которая предоставляет одну из немногих оставшихся возможностей для поддержания институционализированного диалога с участием России, ЕС и всех его государств-членов.

14 См.: Стамбульский документ 1999 года // Официальный сайт ОБСЕ. С. 45 - 47. URL: https://www.osce.org/files/f/documents/7/1/39573.pdf.

15 Council of the European Union. Draft Council Conclusions on EU-OSCE Cooperation in Conflict Prevention, Crisis Management and Post-Conflict Rehabilitation. Doc. No. 14527/1/03, 10 November 2003 // Официальный сайт EC. URL: https://data.consilium.europa.eu/doc/documen t/ST-14527-2003-REV-1/en/pdf.

16 Ibid. P. 2.

17 Правила процедуры Организации по безопасности и сотрудничеству в Европе. Документ MC.DOC/1/06, 1 ноября 2006. C. 9, 11 // Официальный сайт ОБCE. URL: https://www.osce. org/files/f/documents/2/4/22780.pdf.

18 First EU-OSCE high-level meeting takes place in Brussels // European External Action Service. 2018. 12 December 2018. URL: https://eeas.europa.eu/headquarters/headquarters-homepage/55370/first-eu-osce-high-level-meeting-takes-place-brussels_en. См. также: Strengthening OSCE-EU Co-Operation Discussed at First Annual High-Level Meeting Held in Brussels // Официальный сайт ОБСЕ. 2018. 13 декабря. URL: https://www.osce.org/secretary-general/40 6682.

19 Organisation for Security \& Co-operation in Europe (OSCE), Delegation of the European Union to the International Organisations in Vienna // Официальный сайт EC. URL: https://eeas.europa .eu/delegations/vienna-international-organisations/2297/organisation-security-co-operation-euro pe-osce.

20 Working Party on the OSCE and the Council of Europe // European Council, Council of the European Union. URL: https://www.consilium.europa.eu/en/council-eu/preparatory-bodies/work ing-party-osce-and-council-of-europe/.

21 Harsch M.F. The Power of Dependence: NATO-UN Cooperation in Crisis Management. Oxford: Oxford University Press, 2015.

22 The EU provides further satellite imagery support to the OSCE Special Monitoring Mission in Ukraine // European Commission. 2017. 24 March. URL: https://ec.europa.eu/commission/press corner/detail/es/IP_17_729.

23 Biermann R., Koops J.A. Studying Relations Among International Organizations in World Politics: Core Concepts and Challenges // R. Biermann, J.A. Koops (eds.). The Palgrave Handbook of Inter-Organization Relations. - London: Palgrave MacMillan, 2017. P. 22.

24 Исключая операционные расходы Специальной мониторинговой миссии ОБСЕ в Украине.

25 Еще одна проблема в сотрудничестве ЕС с ОБСЕ, особенно значимая в том, что касается первого измерения, связана с тем, что 26 стран-членов ЕС одновременно являются членами НАТО, 30 членов которой входят в ОБСЕ.

26 Remler Ph. The OSCE as Sisyphus: Mediation, Peace Operations, Human Rights. Istituto Affari Internazionali Paper 21/16, April 2021. URL: https:/www.iai.it/sites/default/files/iaip2116.pdf. 
27 Gray B. Intervening to Improve Inter-organizational Relationships // S. Cropper et al. (eds.). The Oxford Handbook of Inter-organizational Relations. - Oxford: Oxford University Press, 2008. P. 664-690.

28 См.: Dijkstra H. et al. Op. Cit. . См. также: Galbreath D. Op. cit.

29 См.: Wolff S. China: A Challenge or an Opportunity for the OSCE? // Security and Human Rights Monitor. 2021. 22 April. URL: https://www.shrmonitor.org/china-a-challenge-or-an-oppo rtunity-for-the-osce-shrm/.

30 В рамках учрежденной в 2014 г. программы к настоящему времени прошли подготовку около тысячи наблюдателей. Программа продлена до 2022 г. См.: OSCE Secretary General, high-level OSCE officials mark fifth anniversary of AUTINT-run pre-deployment training for Special Monitoring Mission to Ukraine in Götzendorf, Lower Austria // Официалный сайт ОБСЕ. 2019. 12 июня. URL: https://www.osce.org/secretary-general/422819. 
